\title{
Efeito da irrigação no desenvolvimento da alface crespa, em ambiente protegido, em Lavras, $\mathrm{MG}^{1}$
}

\author{
Renato C. Vilas Boas ${ }^{2}$, Jacinto de A. Carvalho ${ }^{3}$, Luiz A. A. Gomes ${ }^{4}$, Kleber J. de Souza ${ }^{5}$, \\ Reginaldo C. Rodrigues ${ }^{5}$ \& Alexandre M. G. de Sousa ${ }^{5}$
}

\begin{abstract}
RESUMO
Com este trabalho, objetivou-se avaliar o efeito de lâminas de irrigação sobre o desenvolvimento da alface crespa, em ambiente protegido, na região de Lavras, MG. O experimento foi instalado em casa de vegetação com delineamento em blocos casualizados, em esquema fatorial $2 \times 4$, com quatro repetições. Os tratamentos se constituíram de duas cultivares de alface, Verônica e Hortência, e quatro lâminas de irrigação, 75, 100, 125 e 150\% de reposição de água, em que os resultados permitiram concluir que as duas cultivares de alface responderam igualmente à aplicação das lâminas de irrigação, sendo as massas frescas máximas, total e comercial, estimadas com a aplicação de 249,1 mm (125,8\%) e $244,9 \mathrm{~mm}(123,7 \%)$, respectivamente; plantas com maior número de folhas (23,06 folhas) e maior massa fresca de foIhas (296,43 g planta $\left.^{-1}\right)$ foram obtidas com a aplicação de 235,3 mm (118,8\%) e 243,1 mm (122,8\%), respectivamente; o teor de matéria seca de folhas reduziu-se linearmente em função das lâminas de água aplicadas.
\end{abstract}

Palavras-chave: Lactuca sativa L., manejo da irrigação, irrigação por gotejamento

\section{Effect of irrigation on development of crisped lettuce, in protected environment, in Lavras, MG}

\begin{abstract}
The present work intended to evaluate the effect of irrigation depths on the development of crisped lettuce, in protected environment in the region of Lavras, Minas Gerais State, Brazil. The experiment was set up in a greenhouse with randomized blocks design in $2 \times 4$ factorial scheme, with four replications. The treatments consisted of two lettuce cultivars, Verônica and Hortência, and four irrigation depths, 75, 100,125 and 150\% of water replacement. The results allow to conclude that the two cultivars of lettuce respond equally to application of irrigation depths, with the maximum, total and commercial fresh masses estimated with the application of $249.1 \mathrm{~mm}(125.8 \%)$ and $244.9 \mathrm{~mm}(123.7 \%)$, respectively; plants with higher number of leaves (23.06 leaves) and higher fresh mass of leaves (296.43 $\mathrm{g} \mathrm{plant}^{-1}$ ) were obtained with the application of $235.3 \mathrm{~mm}(118.8 \%)$ and $243.1 \mathrm{~mm}(122.8 \%)$, respectively; the dry matter content of leaves reduced linearly with the applied water depths.
\end{abstract}

Key words: Lactuca sativa L., irrigation scheduling, drip irrigation

\footnotetext{
${ }^{1}$ Extraído da Dissertação de Mestrado do primeiro autor, apresentada à Universidade Federal de Lavras (UFLA). Trabalho financiado pelo CNPq

${ }^{2}$ Mestre em Engenharia Agrícola/Irrigação e Drenagem, Rua João Renato de Pádua 65, CEP 37200-000, Lavras, MG. Fone: (35) 3822-5079. E-mail: renatovilasboas@yahoo.com.br

3 DEG/UFLA. Fone: (35) 3829-1489. E-mail: jacintoc@ufla.br

${ }^{4}$ DAG/UFLA. Fone: (35) 3829-1782. E-mail: laagomes@ufla.br

${ }^{5}$ Graduando em Engenharia Agrícola/UFLA. Fone: (35) 3822-7312. E-mail: alexagricola1@yahoo.com.br
} 


\section{INTRODUÇÃO}

Dentre as hortaliças mais cultivadas em ambiente protegido no Brasil se destacam o pimentão, a alface, o tomate e o pepino (Vecchia \& Koch, 1999). No mercado interno, a região sudeste é responsável por 65\% da produção, destacandose os estados de São Paulo e Minas Gerais (IBGE, 1996). Ressalta-se que, dentre os diferentes tipos de alface comercializados na CEAGESP/SP em 2004, 48,6\%, ou seja, 12.364 toneladas, foram de alface do tipo crespa (Agrianual, 2006).

No cultivo protegido as principais finalidades, quando sob estrutura de proteção, são: anular os efeitos negativos das baixas temperaturas, geada, vento, granizo, excesso de chuva e encurtar o ciclo de produção, além de aumentar a produtividade e se obter produtos de melhor qualidade (Sganzerla, 1995).

O manejo otimizado da irrigação requer uma estimativa sistemática do estado energético de água no solo para determinar as quantidades apropriadas e o tempo de irrigação. O conteúdo de água do solo deve ser mantido entre certos limites específicos acima e abaixo, onde a água disponível para a planta não é limitada, enquanto a lixiviação é prevenida (Morgan et al., 2001).

Andrade Júnior et al. (1992), analisando os efeitos de quatro níveis de irrigação baseados na evaporação do tanque Classe A $(0,50 ; 0,75 ; 1,00$ e 1,25), aplicados por microaspersão em alface, constataram que a massa fresca da "cabeça” e a produtividade, apresentaram respostas quadráticas, alcançando os valores máximos de 184 g e $23.670 \mathrm{~kg} \mathrm{ha}^{-1}$, respectivamente, com o nível de irrigação correspondente a $75 \%$ da ECA.

Hamada (1993), estudando a aplicação de lâminas de água (60, 80, 100 e $120 \%$ da evaporação do tanque Classe A) na cultura da alface tipo lisa, através de gotejo, verificou que o maior valor de matéria seca total acumulada foi de 13 g planta $^{-1}$, conseguida com o tratamento de 100\% da evaporação; já os melhores resultados de produtividade e produção de plantas de melhor qualidade comercial foram obtidos através da aplicação do nível de irrigação equivalente a 1,2 vez à ECA.

Devido à importância do cultivo em ambiente protegido para a cultura da alface no Brasil, torna-se de grande importância o desenvolvimento de pesquisas que subsidiem o aproveitamento do potencial dessa tecnologia nas diferentes regiões climáticas do País, notadamente aqueles necessários ao adequado manejo da irrigação.

Na literatura, vários trabalhos têm mostrado ser a tensão de água no solo indicada não apenas para determinar o momento de irrigar mas também, para mostrar a quantidade de água a ser aplicada nas culturas (Guerra, 1995; Figuerêdo, 1998; Santos \& Pereira, 2004).

Objetivou-se, com o presente trabalho, avaliar o efeito de lâminas de irrigação sobre o desenvolvimento da alface crespa, em ambiente protegido, na região de Lavras, MG.

\section{MATERIAL E MÉTODOS}

O experimento foi conduzido entre os meses de setembro e novembro de 2005 em casa de vegetação, modelo arco, do Departamento de Engenharia da Universidade Federal de Lavras (UFLA), no município de Lavras, sul de Minas Gerais, que está situado a 913,9 m de altitude e com coordenadas geográficas $21^{\circ} 14^{\prime}$ de latitude sul e $45^{\circ} 00^{\prime}$ de longitude oeste de Greenwich (Brasil, 1992).

De acordo com a classificação de Köppen (Antunes, 1980), a região apresenta um clima Cwb, ou seja, clima temperado suave, chuvoso, com inverno seco. Lavras apresenta temperatura do ar média anual de $19,4{ }^{\circ} \mathrm{C}$, umidade relativa do ar média de 76,2\% e tem uma precipitação média anual de $1.529,7$ mm, bem como uma evaporação média anual de 1.034,3 mm (Brasil, 1992).

O solo foi classificado como Latossolo Vermelho Distroférrico (EMBRAPA, 1999), sendo a granulometria e a classificação textural apresentadas na Tabela 1.

Tabela 1. Granulometria e classificação textural do solo utilizado no experimento

\begin{tabular}{lcccc}
\hline Identificação & Areia & Silte & Argila & Classe textural \\
\cline { 2 - 4 } & & $\mathbf{( \% )}$ & & \\
Amostra 1 & 12 & 21 & 67 & Muito argilosa \\
Amostra 2 & 12 & 22 & 66 & Muito argilosa \\
\hline
\end{tabular}

A curva característica de retenção de água no solo é representada pela Eq. 1:

$$
\theta=0,287+\frac{0,290}{\left[1+(0,280 \cdot|\psi \mathrm{m}|)^{2,204}\right]^{0,546}}
$$

em que:

$\theta$ - umidade com base em volume, $\mathrm{cm}^{3} \mathrm{~cm}^{-3}$

$\psi \mathrm{m}$ - potencial matricial, $\mathrm{kPa}$

Empregou-se o delineamento em blocos casualizados em esquema fatorial $2 \times 4$ e se utilizaram oito tratamentos com quatro repetições. Os tratamentos se constituíram de duas cultivares de alface, Verônica e Hortência, e quatro lâminas de irrigação, 75, 100, 125 e 150\% de reposição de água. Para monitorar o estado de energia da água no solo, foram necessários oito tensiômetros instalados a $0,10 \mathrm{~m}$ de profundidade, nos canteiros com 100\% de reposição de água, para cada cultivar, enquanto para obtenção do momento de irrigar foi utilizada a média dos quatro tensiômetros; por outro lado, o manejo da irrigação foi realizado separadamente para as cultivares em estudo. Utilizou-se a tensão de água no solo igual a 15 kPa (Santos \& Pereira, 2004), como referência do momento de irrigar e a lâmina de irrigação de $100 \%$, correspondente a essa tensão. Para se aplicar as lâminas de irrigação de 75, 125 e 150\%, variou-se o número de gotejadores na linha lateral e se utilizaram quatro linhas de plantas, espaçadas $0,30 \mathrm{~m}$ entre si e $0,20 \mathrm{~m}$ entre plantas, totalizando 20 plantas por parcela. Consideraram-se úteis as plantas das linhas centrais nas quais foram descartadas duas plantas no início e duas no final (parcela útil com 6 plantas).

Utilizou-se de sistema de irrigação por gotejamento visto 
que as linhas de gotejo foram inseridas entre duas linhas de plantio em cada parcela e a água distribuída nos canteiros, por meio de tubos de polietileno de diâmetro de $16 \mathrm{~mm}$. Em cada linha dos tratamentos com $100 \%$ de reposição de água se achavam quatro gotejadores instalados a $0,25 \mathrm{~m}$ de distância um do outro. Nos tratamentos com 75, 125 e 150\% de reposição de água havia, em cada linha, três, cinco e seis gotejadores, respectivamente. Utilizaram-se gotejadores da marca Netafim, modelo P. C. J. com vazão de $2 \mathrm{~L} \mathrm{~h}^{-1}$, trabalhando com uma pressão de serviço de $200 \mathrm{kPa}$.

Fez-se o cálculo do tempo de funcionamento do sistema de irrigação a partir da lâmina bruta, calculada de acordo com Cabello (1996), considerando-se a profundidade efetiva do sistema radicular igual a $0,20 \mathrm{~m}$. A eficiência de aplicação de água do sistema foi adotada como 90\%.

As adubações de plantio e cobertura foram realizadas manualmente com base nas análises de solo e conforme recomendação de Gomes et al. (1999). O controle de doenças foi preventivo, utilizando-se o Dithane M45, com uma dosagem de 250 g $100 \mathrm{~L}^{-1}$ de água aos 15 e 30 dias após o transplante das mudas. Desde o transplante (11/10/2005) até o início da diferenciação dos tratamentos (21/10/2005), o fornecimento de água ao solo se deu por meio de um regador manual, uma vez que as raízes se encontravam pouco desenvolvidas; aplicou-se, durante este período, uma lâmina de irrigação diária de 2,67 mm.

As características avaliadas foram massa fresca total e comercial (após se retirar as folhas externas com coloração amarelada e/ou com sintomas de queimadura em suas bordas), número e massa fresca de folhas da cabeça comercial e teor de matéria seca de folhas. Os dados amostrados foram submetidos a análise de variância com a realização do teste $\mathrm{F}$ e análise de regressão a 5 e $1 \%$ de probabilidade.

\section{RESULTADOS E DISCUSSÃO}

No período de condução do experimento as médias de temperatura e a umidade relativa do ar no interior da casa de vegetação foram de $25^{\circ} \mathrm{C}$ e $66,5 \%$, respectivamente. Os valores médios de temperatura e umidade relativa estão de acordo com Sganzerla (1995), que relata que a umidade relativa do ar ótima varia de 60 a $80 \%$ e as temperaturas críticas de interferência no desenvolvimento da cultura da alface se situam abaixo de $10-12^{\circ} \mathrm{C}$ e acima de $30{ }^{\circ} \mathrm{C}$.

Os valores percentuais, inicial e corrigido, de reposição de água ao solo e as lâminas totais de irrigação correspondentes, encontram-se na Tabela 2.

Tabela 2. Percentuais de reposição de água, inicial e corrigido, e lâminas totais de irrigação correspondentes, aplicadas durante à experimentação

\begin{tabular}{ccc}
\hline $\begin{array}{c}\text { Percentual inicial } \\
\mathbf{( \% )}\end{array}$ & $\begin{array}{c}\text { Percentual corrigido } \\
\mathbf{( \% )}\end{array}$ & $\begin{array}{c}\text { Lâmina de irrigação } \\
\text { correspondente }(\mathbf{m m})\end{array}$ \\
75 & 78,3 & 155 \\
100 & 100,0 & 198 \\
125 & 121,2 & 240 \\
150 & 142,9 & 283 \\
\hline
\end{tabular}

Observa-se que a massa fresca, tanto total quanto comercial, foi bastante influenciada pelas lâminas de água repostas ao solo, conforme a Tabela 3 .

Tabela 3. Resumo das análises de variância e de regressão para massa fresca total (MFT) e comercial (MFC), de duas cultivares de alface sob diferentes lâminas de irrigação

\begin{tabular}{|c|c|c|c|}
\hline \multirow{2}{*}{ Fontes de variação } & \multirow{2}{*}{ G. L. } & \multicolumn{2}{|c|}{ Q.M. } \\
\hline & & MFT (g planta-1) & MFC (g planta-1) \\
\hline Bloco & 3 & $9.734,54^{\mathrm{ns}}$ & $7.247,96^{\mathrm{ns}}$ \\
\hline Cultivar & 1 & $1.406,62^{\mathrm{ns}}$ & $398,40^{\text {ns }}$ \\
\hline Lâmina & 3 & $19.692,21$ ** & $17.416,33^{* *}$ \\
\hline Interação & 3 & $3.345,58^{\mathrm{ns}}$ & $2.939,45^{\mathrm{ns}}$ \\
\hline Resíduo & 21 & $3.247,40$ & $2.601,50$ \\
\hline Média Geral & - & 340,66 & 306,98 \\
\hline C.V. $(\%)$ & - & 16,73 & 16,62 \\
\hline Linear & 1 & $40.965,02^{\star *}$ & $32.430,36$ ** \\
\hline Quadrática & 1 & $17.012,75^{\star}$ & $18.716,77^{\star}$ \\
\hline Desvios & 1 & $1.098,86^{\mathrm{ns}}$ & $1.101,87^{\mathrm{ns}}$ \\
\hline Resíduo & 21 & $3.247,40$ & $2.601,50$ \\
\hline
\end{tabular}

${ }^{*} \mathrm{e}^{* *}$ - significativos a 5 e $1 \%$ de probabilidade pelo teste F, respectivamente

Os resultados de massa fresca total e comercial mostraram respostas quadráticas (Figura 1A) com nível de significância de $5 \%$, indicando um acréscimo na massa fresca total e comercial, à medida que se aumentaram as lâminas de irrigação aplicadas até os valores de 249,1 e 244,9 mm que corresponderam a 125,8 e 123,7\% de reposição de água, respectivamente.

É importante ressaltar que as maiores produtividades foram obtidas aplicando-se lâminas de irrigação superiores a 100\% de reposição de água devido, possivelmente, à eficiência global do sistema, ou seja, não houve eficiência de 100\% de absorção de água (houve, sim, perdas por percolação, redistribuição de água no solo e áreas com déficit hídrico).

Andrade Júnior \& Klar (1997), estudando os efeitos de quatro níveis de irrigação baseados na evaporação do tanque Classe A (ECA) $(0,25 ; 0,50 ; 0,75$ e 1,00), utilizando irrigação por gotejamento na cultura da alface tipo americana, também encontraram ajuste quadrático para massa fresca por planta; entretanto, os autores obtiveram o valor máximo de 818,7 g, com nível de irrigação correspondente a 75\% da ECA.

Observou-se redução na MFT e na MFC com a aplicação da lâmina de 283 mm (142,9\% de reposição de água) em função, sem dúvida, dos elevados teores de água no solo terem reduzido o arejamento adequado na região de maior concentração das raízes (Klar, 1991), provocando alterações fisiológicas que levaram à redução da produção da alface e devido à lixiviação de nutrientes (Knott \& Tavernetti, 1944).

O número e a massa fresca de folhas também apresentaram resposta quadrática em relação às lâminas de irrigação (Tabela 4). Ocorreu acréscimo no número e na massa fresca de folhas sempre que se aumentaram as quantidades de água aplicadas, até as lâminas de 235,3 mm (118,8\%) e 243,1 mm (122,8\%) (Figuras 1B e 1C), respectivamente, quando as plantas atingiram 23,06 folhas e 296,43 g planta $^{-1}$ de massa fresca.

Andriolo et al. (2003) obtiveram, em estudo sobre crescimento e desenvolvimento de plantas de alface, cv. Vera, 
A.

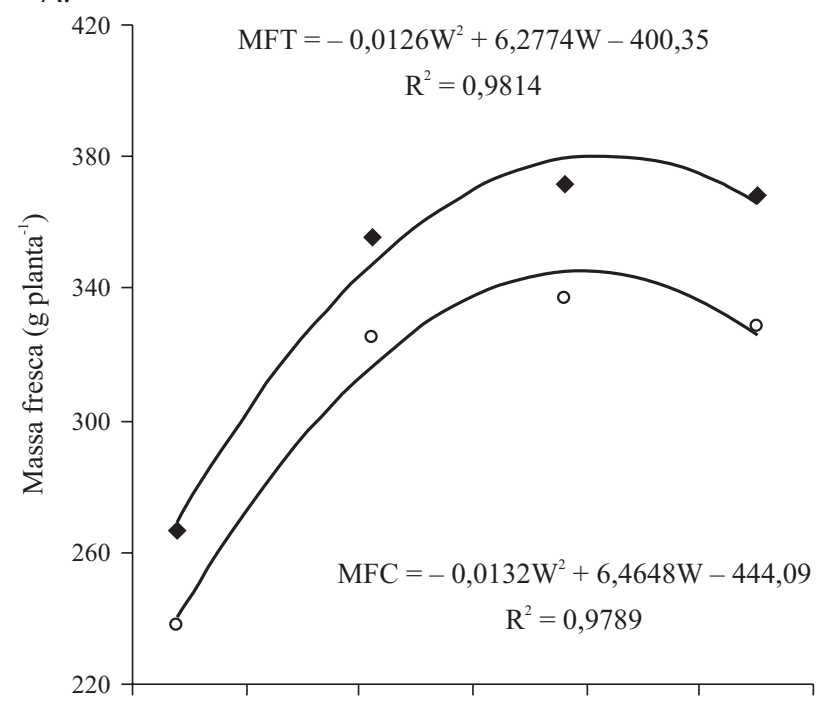

C.

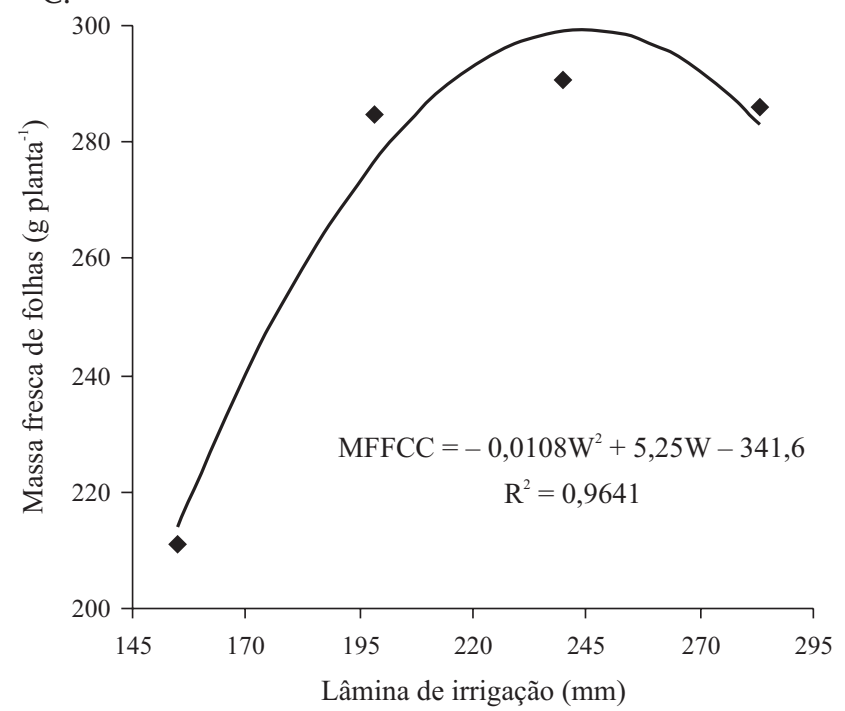

B.

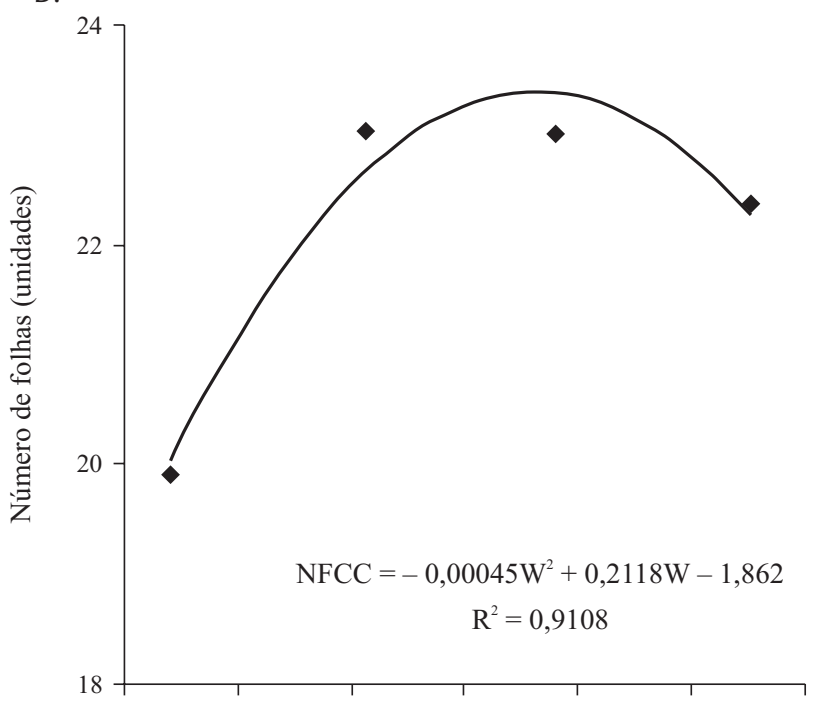

D.

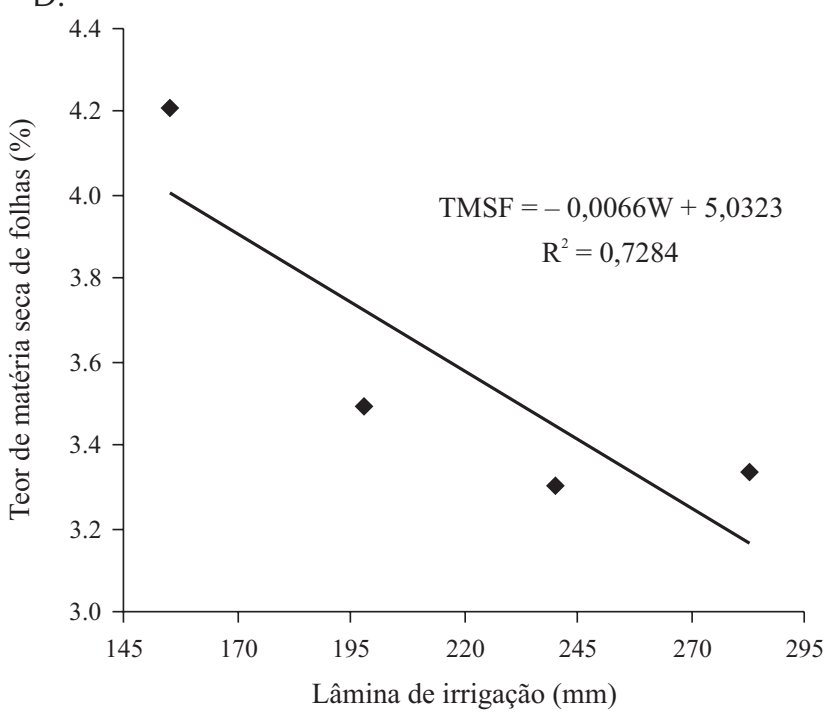

Figura 1. Massa fresca total (MFT) e massa fresca comercial (MFC) (A), número de folhas da cabeça comercial (NFCC) (B), massa fresca de folhas da cabeça comercial (MFFCC) (C) e teor de matéria seca de folhas (TMSF) (D) em função das lâminas de irrigação aplicadas na cultura da alface

Tabela 4. Resumo das análises de variância e de regressão para número de folhas da cabeça comercial (NFCC), massa fresca de folhas da cabeça comercial (MFFCC) e teor de matéria seca de folhas (TMSF) de duas cultivares de alface sob diferentes lâminas de irrigação

\begin{tabular}{lrccc}
\hline $\begin{array}{l}\text { Fontes de } \\
\text { variação }\end{array}$ & G. L. & $\begin{array}{c}\text { NFCC } \\
\text { (unid.) }\end{array}$ & $\begin{array}{c}\text { Q.M.M. } \\
\text { (g planta-1) }\end{array}$ & $\begin{array}{c}\text { TMSF } \\
\text { (\%) }\end{array}$ \\
Bloco & 3 & $2,13^{\text {ns }}$ & $5.096,78^{\text {ns }}$ & $1,40^{\star}$ \\
Cultivar & 1 & $0,00^{\text {ns }}$ & $684,50^{\text {ns }}$ & $1,24^{\text {ns }}$ \\
Lâmina & 3 & $15,46^{*}$ & $11.626,36^{* *}$ & $1,45^{*}$ \\
Interação & 3 & $2,17^{\text {ns }}$ & $2.101,64^{\text {ns }}$ & $0,23^{\text {ns }}$ \\
Resíduo & 21 & 3,70 & $1.700,31$ & 0,35 \\
Média Geral & - & 22,19 & 268,18 & 3,59 \\
C.V. (\%) & - & 8,67 & 15,38 & 16,47 \\
Linear & 1 & $21,11^{*}$ & $21.277,94^{\star *}$ & $3,17^{\star *}$ \\
Quadrática & 1 & $21,13^{*}$ & $12.350,42^{*}$ & $1,14^{\text {ns }}$ \\
Desvios & 1 & $4,14^{\text {ns }}$ & $1.250,72^{\text {ns }}$ & $0,03^{\text {ns }}$ \\
Resíduo & 21 & 3,70 & $1.700,31$ & 0,35 \\
\hline
\end{tabular}

ns - não significativo pelo teste $\mathrm{F}$

${ }^{*} \mathrm{e}^{* *}$ - significativos a 5 e $1 \%$ de probabilidade pelo teste $\mathrm{F}$, respectivamente proveniente de mudas com diferentes idades fisiológicas e cultivadas a céu aberto, o maior valor de 21,20 folhas por planta; já Echer et al. (2000) verificaram, em experimento com cinco cultivares de alface do tipo crespa, valor médio de 22,52 folhas por planta, cultivando no espaçamento de 0,20 x 0,20 m. O valor médio verificado nesse estudo foi de 22,19 folhas por planta, bastante semelhante aos encontrados nos trabalhos citados. Deve-se levar em conta, ainda, que os experimentos foram realizados em condições diferentes, utilizando-se cultivares também diferentes.

Para a massa fresca de folhas da cabeça comercial, o valor médio encontrado no experimento foi de 268,18 g planta $^{-1}$. Santos et al. (1998), estudando o comportamento de dez cultivares de alface adubadas com composto orgânico de lixo urbano na cidade de Viçosa, Minas Gerais, para a cultivar Grand Rapids, obtiveram 202,40 g planta ${ }^{-1}$. Salienta-se que os experimentos foram conduzidos em locais diferentes e com condições ambientais distintas.

A regressão mostra que o teor de matéria seca de folhas 
diminui de forma linear com o aumento da lâmina de irrigação (Figura 1D). O aumento de uma unidade na lâmina de irrigação reduz em 0,0066\% o teor de matéria seca. Andrade Júnior (1994) obteve resultados semelhantes para teor de matéria seca total tendo em vista decréscimo no teor de matéria seca da parte aérea (5,6 a 4,7\%), com o aumento das lâminas aplicadas com base nas frações da evaporação no tanque Classe A (0,25 a 1,00); segundo o autor, as plantas, em virtude da sua maior disponibilidade de água, acumulam mais matéria fresca e reduzem a porcentagem de matéria seca.

Santos \& Pereira (2004), observando o comportamento da matéria fresca da parte comercial e o teor de matéria seca comercial, notaram que mais matéria fresca foi obtida a tensões próximas à da capacidade de campo, por haver mais água disponível, decrescendo linearmente com o aumento da tensão.

\section{CONCLUSÕES}

1. As cultivares de alface, Verônica e Hortência, responderam igualmente à aplicação das lâminas de irrigação, sendo as massas frescas máximas, total e comercial, estimadas com a aplicação de 249,1 mm (125,8\%) e 244,9 mm (123,7\%), respectivamente.

2. Plantas com maior número de folhas (23,06 folhas) e maior massa fresca de folhas (296,43 g planta $\left.^{-1}\right)$ foram obtidas com a aplicação de 235,3 mm (118,8\%) e 243,1 mm (122,8\%), respectivamente.

3. O teor de matéria seca de folhas reduziu linearmente em função das lâminas de água aplicadas.

\section{AgRADECIMENTOS}

Ao Conselho Nacional de Pesquisa e Desenvolvimento Científico e Tecnológico - CNPq, pelo auxílio financeiro, e ao Departamento de Engenharia da UFLA.

\section{LITERATURA CITADA}

Agrianual - Anuário da agricultura brasileira. Alface. São Paulo: FNP, 2006. p.147-148.

Andrade Júnior, A. S. de. Manejo da irrigação da cultura da alface (Lactuca sativa L.) através do tanque classe A. Botucatu: UNESP, 1994. 104p. Dissertação Mestrado

Andrade Júnior, A. S. de; Duarte, R. L. R.; Ribeiro, V. Q. Níveis de irrigação na cultura da alface. Teresina: EMBRAPA-UEPAE, 1992. 16p. Boletim de Pesquisa, n.13

Andrade Júnior, A. S. de; Klar, A. E. Manejo da irrigação da cultura da alface (Lactuca sativa L.) através do tanque classe A. Scientia Agricola, Piracicaba, v.54, n.1/2, p.31-38, 1997.

Andriolo, J. L.; Espindola, M. C. G.; Stefanello, M. O. Crescimento e desenvolvimento de plantas de alface provenientes de mudas com diferentes idades fisiológicas. Ciência Rural, Santa Maria, v.33, n.1, p.35-40, 2003.
Antunes, F. Z. Caracterização climática do cerrado em Minas Gerais. Informe Agropecuário, Belo Horizonte, v.6, n.61, p.52-63, 1980.

Brasil. Ministério da Agricultura e Reforma Agrária. Normais climatológias: 1961-1990. Brasília: Embrapa SPI, 1992. 84p.

Cabello, F. P. Riegos localizados de alta frecuencia (RLAF) goteo, microaspersión, exudación. 3.ed. Madrid: Mundi-Prensa, 1996. 511p.

Echer, M. de M.; Sigrist, J. M. M.; Guimarães, V. F.; Minami, K. Efeito do espaçamento no comportamento de cinco cultivares de alface. Horticultura Brasileira, Brasília, v.18, p.507-508, 2000.

EMBRAPA - Empresa Brasileira de Pesquisa Agropecuária. Centro Nacional de Pesquisa de Solos. Sistema brasileiro de classificação de solos. Rio de Janeiro: Embrapa Solos, 1999. 412p.

Figuerêdo, S. F. Estabelecimento do momento de irrigação com base na tensão de água no solo para a cultura do feijoeiro. Piracicaba: ESALQ, 1998. 94p. Dissertação Mestrado

Gomes, L. A. A.; Silva, E. C. da; Faquin, V. Recomendações de adubação para cultivos em ambiente protegido. In: Ribeiro, A. C.; Guimarães, P. T. G.; Alvarez, V. V. H. (ed.). Recomendações para o uso de corretivos e fertilizantes em Minas Gerais: $5^{a}$ aproximação. Viçosa, 1999. p.99-110.

Guerra, A. F. Tensão de água no solo: efeito sobre a produtividade e qualidade dos grãos de cevada. Pesquisa Agropecuária Brasileira, Brasília, v.30, n.2, p.245-254, 1995.

Hamada, E. Desenvolvimento e produtividade da alface (Lactuca sativa L.), submetida a diferentes lâminas de irrigação, através da irrigação por gotejamento. Campinas: UNICAMP, 1993. 102p. Dissertação Mestrado

IBGE - Instituto Brasileiro de Geografia e Estatística. Censo agropecuário: Sudeste. Rio de Janeiro, 1996. http:// www.sidra.ibge.gov.br. 13 Mar. 2000.

Klar, A. E. Irrigação: freqüência e quantidade de aplicação de água. São Paulo: Nobel, 1991. 156p.

Knott, J. E.; Tavernetti, A. A. Prodution of head lettuce in California. California: Agricultural Extension Service, 1944. 51p. Circular n.128

Morgan, K. T.; Parsons, L. R.; Wheaton, T. A. Comparison of laboratory - and field - derived soil water retention curves for a fine sand soil using tensiometric resistance and capacitance methods. Plant and Soil, Dordrecht, v.234, n.2, p.153-157, 2001.

Santos, I. C. dos; Casali, V. W. D.; Miranda, G. V. Comportamento de dez cultivares de alface adubadas com composto de lixo urbano. Pesquisa Agropecuária Brasileira, Brasília, v.33, n.2, p.157-161, 1998.

Santos, S. R. dos; Pereira, G. M. Comportamento da alface tipo americana sob diferentes tensões de água no solo, em ambiente protegido. Engenharia Agrícola, Jaboticabal, v.24, n.3, p.569-577, 2004.

Sganzerla, E. Nova Agricultura: A fascinante arte de cultivar com os plásticos. 5.ed. Guaíba: Agropecuária, 1995. 342p.

Vecchia, P. T. D.; Koch, P. S. História e perspectivas da produção de hortaliças em ambiente protegido no Brasil. Informe Agropecuário, Belo Horizonte, v.20, n.200/201, p.5-10, 1999. 